\title{
Die „Häresie“ des Echnaton: Aspekte der Amarna-Religion ${ }^{1}$
}

\author{
Von \\ JAN ASSMANN \\ Heidelberg
}

Als Amenophis IV. um das Jahr 1360 v. Chr., im 6. Jahr seiner Regierung, die Hauptstadt Theben verließ und in jene von uns "Amarna" genannte Neugründung übersiedelte, die er sich und seinem Gott Aton in der Provinz aus dem Boden gestampft hatte, vollzog er einen Schritt, der mit allem Herkommen brach. Es war ja nicht nur die Verlegung der Residenz - das hatten andere Pharaonen vor und nach ihm auch getan - es war vor allem die Schrumpfung des königlichen Wirkungskreises, der vorher den ganzen Horizont des Thutmosidenreiches von Nubien bis Syrien erfüllt hatte und nun auf ein paar Quadratkilometer Wüstenrand beschränkt blieb. Denn darauf läuft es hinaus, wenn nur e i n Gott und dieser nur an e in e r Stelle verehrt wird; ein ägyptischer König hatte überall im Land Bauten und Denkmäler zu errichten, die ihn im kultischen Umgang mit den lokalen Gottheiten darstellen. Was aber von Amenopbis $I V$. im Lande gefunden wurde, sind - von einigen Ausnahmen der allerersten und letzten Jahre seiner Regierungszeit abgesehen ${ }^{2}$ - nur die verschleppten Blöcke jener Bauten, die er zunächst in Theben, dann in Amarna errichtet hatte. ${ }^{3}$ Außerhalb dieses Bereichs wurden die Tempel der alten Götter geschlossen und auch dem neuen Gott keine neuen errichtet. So ungeheure Vernachlässigung mußte den Lebensnerv des Landes an einem zentralen Punkt treffen. Für die folgenden 15 Jahre führte es ein Schattendasein, das Tutanchamun später geradezu als "patbologisch", als „Krankbeit des Landes" bezeichnete. ${ }^{4}$

Diesem Ausfall der königlichen Repräsentation im Lande entspricht es, wenn Amenophis $I V$. sich auch in der Durchsetzung seiner neuen Ideen nicht vertreten lassen, sondern

1 Antrittsvorlesung, gehalten am 8. 12. 1971 in Heidelberg. Ein Verzeichnis der verwendeten Abkürzungen findet sich am Schluß.

2 In die Frühzeit Amenophis IV. gehört die Tempelgründung in Sesebi (Sudla), Nubien (Blackman, in: JEA 23, S. 145 ff.; Fairman, in: JEA 24, S. $151 \mathrm{ff}$.), da hier noch verschiedene Götter der traditionellen Religion in Gemeinschaft des Königs dargestellt sind. Eher in die Spätphase der Amarnazeit gehört wohl der Tempel in Memphis, der noch unter Sethos I. erwähnt wird (Spiegelberg, Rechnungen aus der Zeit Sethos I., S. 73 t 16, vgl. ferner Porter-Moss, Topographical Bibliography III, Memphis, 220; Schäfer, in: ZAS 55, S. 20 m. n. 1). - Der Block aus Athribis (JEA 46, S. $80 \mathrm{ff}$.) stammt aus der kurzen Phase einer Korregenz von Amenophis III. und IV.; ebenfalls in die Frühzeit gehören die Funde aus Hierakonpolis (JEA 45, S. 19 ff.; Quibell, Hierakonpolis II, S. 53). - Aus der eigentlichen Amarnazeit ist nur eine sichere Tempelgründung Amenophis' IV. nachgewiesen, und zwar im Zusammenhang des einzigen der alten Kulte, der auch in der Amarnazeit noch geduldet war: für den Sonnengott Re in Heliopolis (s. L. Habachi, Akhenaten in Heliopolis, in: Festschrift Ricke [1971], S. 35 ff.).

3 Die Blöcke aus Luxor, Armant, Medamud sind meines Erachtens aus Karnak, die aus Hermupolis, Assiut und anderen mittelägyptischen Orten aus Amarna verschleppt. Die bekannten Amarna-Briefe, deren Existenz vielleicht auf eine besondere Horizonterweiterung in dieser Zeit schließen lassen könnte, illustrieren ganz im Gegenteil die geschilderte Einengung auch im Bereich der Außenpolitik. Dem entspricht, daß es jetzt, im Gegensatz zur Frühzeit Amenophis IV., keinen „Vizekönig von Kusch" mehr gegeben zu haben scheint.

${ }^{4}$ Urk IV, 2027.11-12: „Das Land war wie krank, die Götter hatten sich von diesem Land abgewendet." Ahnlich nimmt auch Sethos I. zur Amarnazeit Stellung (S. Schott, Der Denkstein Sethos I., in: NAWG (1964) S. 1, 18 u. 38). 
alles persönlich in die Hand nehmen wollte. Alles, was in Amarna zutage kam, jedes Bauwerk, jede Darstellung, jede Inschrift, ist von einem einzigen entwerfenden Geist geprägt und daher - bei aller Neuheit und oft auch Schönheit - von so stereotyper Einheitlichkeit, daß auch weitere Grabungen die Belege nur vervielfachen, aber nichts entscheidend Neues zutage bringen dürften ${ }^{5}$.

Ein Fundstück steht freilich noch aus, das auch in diesem so eindrucksvoll geschlossenen Bilde noch eine empfindliche Lücke schließen könnte: ein Papyrus mit der Lehre des Königs. Der König muß vor allem durch Unterweisung geherrscht haben, und der Kreis derer, die sich in ihren Grabinschriften dieser Unterweisung rühmen (Höflinge, Generäle, Priester, Verwalter, Handwerker, Bildhauer, Architekten) ist genau so allumfassend, wie die Gebiete, auf denen die Neuerungen in all ihrer Kraßheit und Unverwechselbarkeit in Erscheinung treten ${ }^{6}$. Der gewaltsame Bruch mit der Tradition, der sich in den äußeren Fakten als eine alles umfassende Umwälzung darstellt, hatte in dieser Lehre seine geistige Fundierung. Niemand hat je bezweifelt, daß sich diese Lehre vor allem gegen die traditionelle Religion gewendet haben muß, und man hat gerne von einer "Häresie" gesprochen und Amenophis IV. als „Ketzer“ bezeichnet.

Hier ist man nun zum Glück nicht auf Rekonstruktionen angewiesen. Die vielen Hymnen und religiösen Texte in den Beamtengräbern ${ }^{7}$ gehen - wie alles in Amarna - unmittelbar auf königliche Inspiration, zum Teil sogar Verfasserschaft zurück. Wer nun aber erwartet, in der wissenschaftlichen Erschließung dieser Quellen die geistigen Grundlagen des Umsturzes, die unversöhnlichen Gegensätze zur Tradition klar herausgearbeitet zu finden, wird mit Überraschung feststellen, daß die meisten und gerade die neuesten Beiträge zu diesem Thema auf das Gegenteil hinauslaufen. So hat man diese Gegensätze etwa als eine „dogmatische Finesse " eingeschätzt ${ }^{8}$, und das kürzlich erschienene AmarnaKapitel der "Cambridge Ancient History" spricht von einer „bloßen Nuance ".9

Diese Einschätzung gewann an Boden, als immer mehr isolierte Motive aus Amarna sich auch in älteren Texten und Darstellungen nachweisen ließen ${ }^{\mathbf{1 0}}$. In der Freude des Fin-

5 Auch das gilt, wohlgemerkt, nur für die Amarnazeit im eigentlichen Sinne. Die Bauten der thebanischen Jahre, deren Blöcke laufend aus dem IX. Pylon des Karnak-Tempels geborgen werden (s. zuletzt S. Sauneron und Ramadan Saad, in: Kêmi 19 [1968] S. 137-178), zeigen offenbar ein variantenreicheres Bild, das noch manche Uberraschung gewärtigen läßt.

6 Die Amarna-Belege vollständig bei Erman, Die Religion der Ägypter (1934) S. 122 m. n. 1-8, dazu als Zeugnis eines Bildhauers das Assuan-Graffito des Baki (Sandman, 175.6-7 "Den S. M. selbst unterrichtet hat"); H. Brunner, Altägyptische Erziehung (1957) 52-53. Die Fülle der Belege zeigt eindeutig, daß es sich hier nicht um ein konventionelles Klischee handelt, sondern wirklich um eine als neuartig und erwähnenswert empfundene Form königlicher Unterweisung, ähnlich der als „Weg des Lebens" bezeichneten Lehre des Königs Harembab, aus der sein Karnak-Dekret Auszüge festhält (Urk IV, 2156.8 ff.).

7 Bequem zusammengestellt in der Edition von Sandman.

${ }^{8} A$. Piankoff, The Shrines of Tutankhamun (1955) $12 \mathrm{f} . ;$ ders., in: Bulletin de la Societé Française d'Égyptologie 28-29 (1959) S. 7-14; ders., in: Bull. de l'Institut Française d'Archéologie Orientale 62 (1964) S. 207-218. Zum gleichen Ergebnis kommt, unter Berufung auf Piankoff, C. Aldred, Akhenaten, Pharaoh of Egypt: a New Study (1968), bes. S. 164-168.

9 Aldred, in: CAH 19 (2. Aufl. 1971) S. 40-43, speziell S. 41.

10 Bahnbrechend gewirkt hat ein Aufsatz von G. Möller, der nachweisen konnte, daß eine Handschrift mit besonders stark an Amarnatexte anklingenden Hymnen nicht in die Nachamarnazeit, sondern weit davor, in die Zeit Amenophis II. oder sogar in die 17. Dynastie zu datieren ist (ZAS 56 [1920] S. 34 ff.; inzwischen hat sich, was allgemein übersehen wird, durch die Auffindung eines Paralleltexts auf einem Statuenfragment der Zweiten $Z$ wischenzeit der frühe Ansatz bestätigt, s. S. Hassan, Hymnes Religieux du Moyen Empire [1930] S. 157 ff.; der Text ist also kein unmittelbarer Vorläufer der Amarna-Bewegung, sondern gehört vielmehr in eine Tradition der Weisheits- 
dens und Vergleichens übersah man allerdings of, daß in Amarna jedes Detail in einem so engen Gesamtzusammenhang steht, daß es nicht herausgegriffen werden kann, ohne seinen Sinn zu verändern, und von dem Sinnzusammenhang der traditionellen Sonnenreligion, in den man diese Vorläufer und Frühformen der Amarna-Religion einfügen wollte, hatte man, um es offen zu sagen, kaum eine Vorstellung. So konnte es zu der Auffassung kommen, die heute fast communis opinio ist: daß Echnaton die traditionelle Sonnenreligion lediglich auf Kosten aller übrigen Kulte verabsolutiert, nicht aber etwas eigentlich Neues eingeführt habe.11

$*$

Nachdem ich mich nun seit einigen Jahren der traditionellen Sonnenreligion und der Sammlung der im Lande verstreuten Denkmäler gewidmet habe, die sich mit ihr in Verbindung bringen lassen, glaube ich so etwas wie eine Basis gewonnen $\mathrm{zu}$ haben, von der aus man versuchen kann, auch die Amarna-Religion neu in den Blick $\mathrm{zu}$ fassen. Ich möchte daher mit einer Darstellung dessen beginnen, was ich als die traditionelle Sonnen-

literatur des Mittleren Reichs, die uns etwa in einem berühmten Abschnitt der „Lehre für Merikare" [P 130-138] und im sog. "Nilhymnus" greifbar ist). Kurz darauf widmete W. Wolf diesem und anderen „Vorläufern der Reform Echnatons" einen noch heute grundlegenden Aufsatz, in: ZÆ̈S 59 (1924) S. $109 \mathrm{ff}$.

11 Eine andere, sich in jüngerer Zeit durchsetzende Auffassung bringt diese „Vorläufer" nicht mit der traditionellen Sonnenreligion in Zusammenhang, sondern sieht darin Anzeichen einer weit vor Amenophis IV. zurückreichenden sektenhaften Verehrung desselben Gottes Aton (J. und $M$. Doresse, Le culte D'Aton sous la xviii. ème dynastie avant le schisme amarnien, in: Journal asiatique 233 [1941-42] S. $181 \mathrm{ff}$;; Kees, Der Götterglaube im Alten Ägypten (1941, 21956) S. 368 f.; Hayes, in: CAH II, 9.1 [1962] S. 33). Als Kronzeugen für diese Hypothese gelten vor allem drei Denkmäler:

1. Ein Skarabäus Thutmosis IV. (JEA 17, S. 23-25; JEA 22, S. 3-6), dessen Inschrift „die Sonne" (jtn: Aton) wie einen handelnden Gott darstellt, dazu Schreibungen des Wortes jtn "Sonne" mit Gottesdeterminativ seit dem Mittleren Reich (Fecht, in: ZAS 85, S. 113);

2. Der Block Berlin 2072 (Schäfer, in: ZAS 52, S. 73; ZAS 55, S. 7; Sitzungsber. d. Preuss. Akad. d. Wiss. [1919], S. 477 f.), der bereits den "Lehrhaften Gottesnamen" (s. u. S. 117) enthält und von Schäfer in die Zeit Amenophis III. datiert wird, dazu die bedeutende Rolle des Epithetons thbn jtn "die Sonne erglänzt" als Name Amenophis III. (Hayes, in: JNES 19, S. 179; CoA III, S. 200 d);

3. Die Stele der beiden Baumeister Suti und Hor (s. zuletzt Fecht, in: ZAS 94 [1967], S. 25-50).

Hierzu ist Folgendes zu bemerken: Der Stelentext (3.), der in die Zeit Amenophis III. datiert ist, repräsentiert unbestreitbar eine „Frübform der Amarna-Theologie" (Fecht). Er ist das nicht vereinzelte Zeugnis einer Ubergangszeit gegen Ende der Regierung Amenophis III., die auf den wachsenden Einfluß Amenophis IV. und wohl auch eine kurze Korregentschaft schließen läßt. Auf dem Berliner Block (2.) ist der Gottesname nachträglich über einer getilgten älteren Inschrift angebracht. Der Skarabäus (1.) verwendet in dem Satz jtn $r$ b t.f "die Sonne ist vor ibm, ibm voraus" das Wort jtn im gewöhnlichen Sinn ("Sonne") als Metapher für die "Strablkraft" des zum Feldzug ausziehenden Königs (im letzten Satz der Inschrift lies statt jtn eher jtj-f „sein Vater"). Das Wort jtn "Sonne" ist $\mathrm{n} \mathrm{i} \mathrm{c} \mathrm{h} \mathrm{t} \mathrm{der} \mathrm{Name} \mathrm{des} \mathrm{Gottes} \mathrm{von} \mathrm{Amarna} \mathrm{(so} \mathrm{nur} \mathrm{als} \mathrm{Bestandteil} \mathrm{theo-}$ phorer Eigennnamen; die Texte verwenden, wo sie den Gott meinen, das Wort stets mit charakterisierenden Zusätzen wie „groß und lebend" ${ }^{\text {") }}$, sondern das normale ägyptische Wort für „Sonne", das in religiösen Texten seit dem frühen mittleren Reich aufkommt und sich in dem Maße verbreitet, wie es, aus theologischen Gründen, nötig wird, zwischen „Sonne (jtn) und "Sonnengott" $\left(R c_{w}, R e\right)$ zu unterscheiden. In Amarna wird eine solche Dissoziation von Gott und Gestirn gerade aufgehoben: eine Wendung wie „seine (des Sonnengottes) Sonne" wäre in einem Amarnatext undenkbar. 
religion verstehe und muß mich dabei auf eine notwendigerweise summarische Skizze beschränken. ${ }^{12}$

Dieser Kult gilt eher, um das vorweg zu sagen, einem Vorga n g als einem G o t t. Das macht schon die Ikonographie deutlich. Kein ägyptischer Kult, auch nicht der von Amarna, kommt ohne bildliche Darstellungen seines Vollzugs aus, und so lassen sich wesentliche Punkte einer Gottesvorstellung und der Konzeption eines kultisch geformten Umgangs mit einer gegebenen Gottheit schon an diesen Darstellungen ablesen. Die typische, sozusagen „kanonische“ Sonnenkult-Darstellung, wie sie zum Bildschmuck jedes ägyptischen Sonnenheiligtums des Neuen Reiches gehört, zeigt den Gott in einer Barke im Vollzug jener Bewegung, die den Wechsel von Tag und Nacht hervorbringt. Die meisten dieser Bilder stellen den Vorgang in zwei Phasen dar, als Ausfahrt am Morgen und Landung am Abend ${ }^{13}$, aber es gibt auch Darstellungen einer Mittags- und Nachtphase ${ }^{14}$ und sogar Zyklen, die den Gott in den 24 Stunden des Tages und der Nacht zeigen ${ }^{15}$. Der Sonnengott wandelt in diesen Darstellungen mit jeder Phase seine Gestalt. Er wird am Morgen als Kind und Käfer, am Mittag als falkenköpfiger Mann und am Abend als Widder oder widderköpfiger Mann dargestellt.

Die Darstellungen der Barkenfahrt zeigen den Sonnengott nie allein, sondern immer im Kreise einer Begleitmannschaft beistehender Gottheiten, deren Zusammensetzung ebenfalls mit jeder Phase wechselt. Da finden sich große Gottheiten wie Isis, Hathor, Horus, Seth, Thoth und Maat neben nur hier belegten Sondergöttern wie Lenker der Barke und Wächter und Begriffs-Personifikationen wie Erkenntnis, Zauber und Machtwort. Alle Gottheiten haben ihre feste Rolle in diesem Vorgang der Barkenfahrt, alle stehen für bestimmte Eigenschaften und Kräfte, die bei diesem Geschehen wirksam werden. Schließlich zehören zur Umgebung des Sonnengottes noch Wesen, die ihn am Morgen begrüßen und am Abend empfangen: Paviane und Schakale. Sie stehen deutlich erkennbar für den äußersten Osten und Westen der dem Ägypter bekannten Welt, also für jene Grenzbereiche, die er dem Himmel besonders nahe glaubte. ${ }^{16}$ Ihrer Rolle entspricht die des irdischen Sonnenpriesters, der denn auch gerne inmitten jener jenseitigen Verehrergruppen dargestellt wird. Wie in allen sonstigen Kultszenen ist dies stets der König, der einzige zum kultischen Umgang mit den Göttern legitimierte Erdenbewohner.

Zwei entgegengesetzte, aber unlösbar zusammengehörende Tendenzen werden schon an dieser Ikonographie des Sonnenkults deutlich, die für die Struktur des altägyptischen Polytheismus überhaupt kennzeichnend sein dürften und diesen, wie sich zeigen wird, in scharfen Gegensatz zur Amarna-Religion stellen:

1. Die Tendenz zur Aufspaltung und Vervielfachung einer Gottesgestalt, wenn etwa, wie hier, der e in e Sonnengott in mehrfachen Namen und Gestalten verehrt wird, als aufgehende, über den Himmel fahrende und untergehende Sonne, und wenn spezifische

12 Für Einzelheiten und Belege s. J. Assmann, Liturgische Lieder an den Sonnengott (1969); ders.: Der König als Sonnenpriester (1970); ders.: Zwei Sonnenhymnen der späten xviii. Dynastie..., in: MDIK 27.1 (1971) S. 1-33.

13 Z. B. König als Sonnenpriester, S. 3-5.

14 Vier-Phasen-Zyklen finden sich z. B. auf vielen pyramidenförmigen Denkmälern des Neuen Reiches dargestellt.

15 Das sog. "Stundenritual“ (Liturgische Lieder, S. 113-164), von dem jetzt, nach freundlicher Mitteilung von Dr. E. Graefe, im thebanischen Grab des Padiborresnet aus der Saitenzeit (Nr. 196) ein vollständiges Exemplar zutage getreten ist. Für die Tagesstunden vgl. ferner das „Buch der Gestalten des Sonnengottes" (Liturgische Lieder, S. 43 n. 17), für die Nachtstunden die sog. "Jenseitsbücher" Amduat und Pfortenbuch (Übersetzung von E. Hornung im Artemis-Verlag angekündigt).

16 S. J. Assmann, Der König als Sonnenpriester (1970) S. 48-53. 
Attribute, Eigenschaften oder Wirkungsweisen als Hypostasen personifiziert werden, wie Erkennen, Zauber und Ausspruch;

2. die Tendenz zur unterordnenden Gesellschaftung von ursprünglich ganz verschiedenen Göttern um einen Hauptgott im Sinne der ihm zur Verfügung stehenden Fähigkeiten, wie die Göttin Maat als Richtigkeit, Ordnung, Thot als Berechnung, Isis als Zauberkraft, Seth als aggressive, vernichtende Gewalt, die Glut der Sonne. ${ }^{17}$

Aus beiden zusammenwirkenden Tendenzen bildet sich um einen Gott in sowohl von außen angezogenen als auch von innen herausprojizierten Göttergestalten eine ihn umgebende Gesellschaft, die ich die "Sphäre des Seinigen" nennen möchte. Im Sonnenkult gibt es, ebenso wie in anderen ägyptischen Kulten, Litaneien, die nichts anderes darstellen als eine Anrufung all dessen, was für den Sonnengott diese "Sphäre des Seinigen" konstituiert $^{18}$. Dazu gehören auch Gegenstände wie „seine Scheibe", nämlich die Sonne, die der Gott als Attribut besitzt und meist als Kopfschmuck trägt, und die beiden Barken der Tages- und Nachtfahrt. Alle stehen sie hier auf einer Stufe und bilden zusammen den komplexen Gottesbegriff, dem dieser Kult gilt.

Derselbe Gottesbegriff liegt nun auch den im Sonnenkult verankerten Hymnen zugrunde ${ }^{19}$. Auch diesen Texten geht es nicht eigentlich um das Lob des Sonnengottes, sondern um die Schilderung des S o n n e $\mathrm{n} l$ a $\mathrm{u} s$, aber doch in einer besonderen Form, die ganz auf den Gott zugeschnitten ist. Die Bewegung der Sonne wird als Schicksal des Gottes im Zusammenwirken der Gottheiten dargestellt, die ihn als „Sphäre des Seinigen" umgeben. Hier finden wir Thoth und Maat, Seth und Horus wieder und besonders auch die jenseitigen Gemeinden der Sonnenaffen, Schakale und Unterweltsbewohner, in deren Sonnenanbetung sich der Hymnus selbst darstellt. Dazu kommen die Gottheiten der kosmischen Räume, die die Sonne bei ihrem Lauf durchmißt: die Himmelsgöttin $N u t$, der Urozean $N u n$, O s iris als Gott der Unterwelt und $T$ a te $n$ e $n$ als Gott des Erdinneren. In dieser Darstellung nimmt der kontinuierliche Prozeß der Sonnenbewegung differenzierte Formen an. Schon der eine Gott selbst erscheint auch hier wieder in verschiedenen Gestalten und Rollen: als Kind, Jüngling, siegreicher Herrscher und verklärter Toter, als Himmelskönig und Totenrichter, als festlich Ausziehender und ins Allerheiligste Zurückkehrender. Ebenso wechselt die den Gott in seinigen jeweiligen Erscheinungsformen umgebende "Sphäre des Seinigen": zum Morgen, zu Geburt und Aufzucht, gehören andere Gottheiten als zum Abend, zu Sarglegung und Wiedergeburt, und wieder andere begleiten ihn in der Barke über den Himmel und helfen ihm bei der Vernichtung der Mächte, die sich ihm in den Weg stellen. Die Gemeinden, die ihn am Abend empfangen, sind andere als die, die ihn am Morgen begrüßen.

Es würde zu weit führen, Beispiele solcher Hymnen vorzuführen, aber schon aus dem Gesagten mag deutlich geworden sein, wie viel diese auf Differenzierung zielenden Texte vom Sonnenlauf zu erzählen haben, auch wenn hier von Sonne und Licht, von der Natur und den Menschen nicht die Rede zu sein scheint. Solange man aber den Sinn dieser Sonnenmythologie nicht versteht, bleibt auch dunkel, wogegen sich die Amarnareligion eigentlich gestellt hat.

Vielleicht kommt man, wenn ich das in notwendig skizzenhafter Vereinfachung zu umreißen versuchen darf, dem Sinn solcher hymnischer Schilderung des Sonnenlaufs mit dem Begriff der I d e n t if $\mathrm{i} k$ a $\mathrm{t}$ i o n etwas näher. Diese Darstellungen des Sonnenlaufs

17 Im gleichen Sinne deutet auch H. te Velde, Seth, God of Confusion (1967) S. 105-108 diese Form der Götter-Gesellschaftung.

18 Einige Belege in: Liturgische Lieder, S. 351 n. 61.

19 Zum Folgenden s. besonders Liturgische Lieder, S. 333-359. 
zielen, wie gesagt, auf Vielheit und Differenzierung. In ihrem Blick steht nicht nur der angeredete Gott, sondern vor allem auch die Welt, die zu ihm in Beziehung gesetzt wird. Himmel, Erde, Wasser und Unterwelt, Tageszeiten und Himmelsrichtungen, aber auch Ereignisse des Kults und des Königtums sowie Ordnungen und Wendepunkte des menschlichen Lebens gewinnen in dieser Mythologie Gestalt. Die Phasen oder Episoden des kosmischen Vorgangs: Geburt und Aufzucht, Anbetung und Verkündung, siegreiche Fahrt, Kampf, Gericht und Fest, Landung, Heimkehr und Empfang, Vereinigung mit der Mutter und Wiedergeburt, geben Brennpunkten des irdischen Daseins eine urbildhafte Gestalt.

Das eindringlichste Beispiel vielleicht ist die Interpretation des Sonnenuntergangs als Tod, als Heimkehr zur Mutter und Wiedergeburt, die eine auch in der Totenliteratur reich zu belegende Beziehung von Sonnenlauf und Totenschicksal herstellt. In der Welt der Lebenden wäre hier vor allem auf die eigentümliche Gleichsetzung der politischen Feinde Ägyptens mit den Feinden des Sonnengottes zu verweisen. Die Himmelsüberquerung der Sonne wird so zum Inbegriff jeder Uberwindung und gesicherten Wohl-Fahrt. Der mythisch gedeutete Sonnenlauf stellt Urbilder bereit, in denen sich Irdisches spiegelt, und Konstellationen, in die der Mensch eintreten kann. So tritt er auch als Sonnenpriester in die Rolle der Sonnenaffen ein, wie es die bildlichen Darstellungen zeigen und ein Totentext ausspricht: ${ }^{20}$

\section{"Ich babe der Sonne Hymnen gesungen, ich habe mich unter die Sonnenaffen gesellt, ich bin einer von ibnen."}

Im Kult legitimiert sich der Sonnenpriester damit, daß er

$$
\begin{aligned}
& \text { "die geheime Rede kenne, die die östlichen Seelen (die Paviane) } \\
& \text { sagen, wenn sie dem Sonnengott Jubellieder anstimmen." } 21
\end{aligned}
$$

Sein Hymnus ist demnach aus solchem Wissen heraus gesprochen, und versteht sich als ein Einstimmen in den jenseitigen Lobpreis.

Kein Wunder daher, daß die M e $\mathrm{n} \mathrm{s} \mathrm{h}$ e $\mathrm{n}$ in diesen Texten keine Rolle spielen. Uberhaupt geht es hier um die Welt, in der die Menschen und der Sprecher selbst leben, nur in jener übertragenen Form eines Wechselspiels göttlicher Handlungen und Schicksale, in dem die Welt gleichsam mythologisch verkörpert ist. Sie kann daher dem Gott nicht als Objekt gegenübergestellt werden: als Objekt seiner Erschaffung, Erhaltung, Beherrschung und Besorgung. Die Intentionen solchen Sprechens sind nicht Dank und Lobpreis des Geschöpfs für den Schöpfer, sondern der abbildende Mitvollzug der himmlischen Vorgänge in Form einer sprachlichen Darstellung der im Sonnenlauf aktivierten „Sphäre des Seinigen". Man darf diese Texte daher nicht unbesehen mit den Amarna-Hymnen auf eine Stufe stellen. Sie gehören unablösbar in den Kult und in die jeweilige Phase des Sonnenlaufs, die morgendliche, abendliche oder gar stündliche hinein, die das mitwirkende Sprechen des ägyptischen Priesters erforderte. So "dramatisch" wie diese Sprechsituation ist

20 Totenbuch Kap. 100 und 129, übersetzt bei Barguet, Le livre des morts (1967), S. 138; vgl. Liturgische Lieder, S. 344 f. und: König als Sonnenpriester, S. 53 m. n. 1-2. Selbst Amenopbis IV. hat während seiner thebanischen Jahre noch diesem Gedanken gehuldigt. Aus einem seiner thebanischen Tempel stammt das Fragment einer Affenstatue (ASAE 7, S. $228 \mathrm{f}$.) und ein unveröffentlichter Block in München (Inv. ÄS 5338) stellt den König auf dem Boden ausgestreckt in engster Gemeinschaft dreier anbetender Paviane dar.

21 König als Sonnenpriester, S. 21 und 48-49. 
daher der in diesen Texten greifbare Gottesbegriff. Es ist gar nicht anders zu erwarten, als daß Texte, die nicht den Sonnenlauf abbildend mitvollziehen, sondern das Wesen des Sonnengottes preisen und verkünden wollen, ganz Anderes zu sagen haben.

Auch solche Texte hat es lange vor Amarna gegeben. In ihnen erscheint derselbe Sonnengott durchaus als ein Gott, der der Welt als seiner Schöpfung in „einsamer Alleinigkeit" gegenübersteht. "Der Eine Einsame" wird er genannt, „der das Seiende schuf", 22 oder: "Der Eine Einsame mit seinen vielen Armen" ${ }^{23}$, wo Einheit und Vielheit verbunden sind, wie in einer anderen Formel: „Der Eine Einsame mit vielen Gestaltungen “ ${ }^{24}$ Diese "Arme" oder "Gestaltungen" des Einen Gottes sind die vielen Götter. „Meine Gestaltungen - das ist jeder Gott" ${ }^{\star}$, sagt der Sonnengott in einer mythologischen Geschichte von sich. ${ }^{25}$ Die Götter sind nicht die Welt, aber sie beseelen, erhalten, formen sie. „Meine Gestaltungen (also: die Götter) sind bei dem, was ich geschaffen babe", sagt der Sonnengott in einem anderen Text ${ }^{26}$. Die ägyptische Theologie ist unerschöpflich in Formulierungen, die die Vielheit der Götter mit der Einheit verbinden. Sie werden als W' o r t e gedeutet, die der Eine am Anbeginn sprach, als seine vielen Namen, als Glieder seines Leibes, als seine Lebensgenien, seine Abbilder usw. ${ }^{27}$

Die dem mythischen Denken allzeit nächstliegende Veranschaulichung einer solchen

22 Pap. Boulaq 17 (der in n. 10 erwähnte Text) vi, 2-3.

23 Ebd., vi, 7. Die übliche Deutung der "Arme" als "Sonnenstrablen" wertet die Stelle als Vorwegnahme des "Strablenatons" Echnatons im Sinne eines "literarischen Bildes" (s. zuletzt Hornung, in ZÄS 97 [1971] S. 75). Da hier aber von den Armen des S ch ö p fe r - Gottes die Rede ist, halte ich die hier vertretene Deutung (Vielarmigkeit als Metapher für die differenzierte Aktivität des anthropomorphen Schöpfergottes) für ebenso möglich.

${ }^{24}$ Davies, The Tomb of Nefer-hotep at Thebes I, Tf. 27, in Bezug auf Osiris (frühe NachAmarnazeit, wahrscheinlich unter Eje).

${ }^{25}$ "Isis und Re“, Pap. Turin Pleyte und Rossi, Tf. 132.11 (besser bei Möller, Hieratische Lesestücke II Tf. 30,12) = Pap. Chester Beatty XI rto. 2,4 = Černý-Gardiner, Hieratic Ostraca I, Tf. ii rto. 8, übersetzt bei E. Brunner-Traut, Altäg. Märchen (1963) S. 117. Vgl. ferner Aussagen wie "Du bist der Schöpfer der Götter, deiner bprwe (Pap. Berlin 3055, XIX, 3) und „deine bprw sind sie (die Götter) allesamt" (Pap. Leiden J 344, vso. x, 10).

${ }^{26}$ Pap. Leiden J 346,iii,10 (ed. Stricker, Spreuken tot beveiling gedurende de schrikkeldagen, in: OMRO 29 [1948] S. 65):

\author{
„Mein Name ist im Himmel, \\ meine Strablen sind auf Erden, \\ meine bprw sind bei dem, was ich geschaffen babe."
}

${ }^{27}$ „Der seine Namen schuf, der Herr der Götterneunbeit“ nennt sich der Schöpfergott im 17. Totenbuchkapitel. Das wird im selben Text erklärt als „Re, der die Namen seiner Glieder schuf, (woraufhin) die Götter entstanden, die nach ibm (kamen)." "Alle seine Glieder sprachen mit ibm", so beschreibt ein Hymnus aus der Zeit Amenophis II. diese erste Phase der Schöpfung (ASAE 42 [1943] Tf. IV 1.11). In den CT ist mit Bezug auf dieselbe Phase oft von den "Millionen Ka's (Lebensgenien)“ des Schöpfergottes die Rede (CT I 376/77c; III 383e; VI 270g vgl. auch I 393c), vgl. Otto, in: Saeculum 14 (1963) S. 277 f. Aus Amun-Hymnen der Nach-Amarnazeit gehören hierher die Sätze "Die Neunbeit ist vereinigt in deinem Leibe, jeder Gott ist dein Abbild (Pap. Leiden I 350,iv, 1 dazu Zandee, De Hymnen aan Amon, in: OMRO 28 [1947] S. 66 f.); "Jeder Gott ist dein Schatten" (Pap. Leiden J 344 vso., $\mathrm{x}, 8-10)$; "Kein Einziger von ibnen (den Göttern) ist frei von deinem Bild" (d. h. „kein Einziger, der nicht dein Abbild wäre": unveröffentlichter Hymnus im theb. Grab 65[6]-[7]; „Dein Ebenbild ist jeder Gott" (Statue Kairo CG 42 208, 6: Legrain, Statues et Statuettes III, 21); „seine Gestalt eignet jedem Gott" (Dekret für Neschons III 35 ed. Golénischeff, Papyrus Hiératiques, 176); „Sein Geschöpf ist jeder Gott" (Statue Kairo Cg 42 232: Legrain, Statues et Statuettes III, 80). 
logischen Struktur ist ihre Verzeitlichung ${ }^{28}$. Da rückt der Einheitsaspekt der Gottheit in die Präexistenz, als, wie es heißt, „noch nicht zwei Dinge in diesem Lande geschaffen waren “ ${ }^{29}$, während die gegenwärtige Welt durch die Zweiheit bzw. Vielheit bestimmt ist ${ }^{30}$. Aber dieses Modell ist nur eine der metaphorischen Veranschaulichungen für die Beziehung von Einheit und Vielheit, in denen das Gemeinte auf verschiedene Weise, aber mit gleichem Wahrheitsanspruch zur Anschauung kommt ${ }^{31}$. In der Vielheit ist der Eine verborgen gegenwärtig, und dieses Paradoxon der verborgenen Gegenwart des Urgottes findet in zahllosen Mythen und lehrhaften Formeln seinen Ausdruck. Hier steht nicht Monotheismus unversöhnlich neben Polytheismus, sondern wir haben die beiden komplementären Aspekte dessen vor uns, was sich als Weltbild aus der mythologischen Terminologie der ägyptischen Texte erschließen läßt.

Wenn ich nun im Folgenden versuchen möchte, dieser so skizzierten traditionellen Konzeption die Amarna-Religion im Sinne einer "Häresie“ gegenüberzustellen, erhebt sich sogleich der Einwand, ob nicht auch dieser erklärtermaßen monotheistische Ansatz im Sinne eines komplementären Aspekts mit der Tradition zu verbinden sei. Wie kann überhaupt jemand als Häretiker auftreten im Rahmen einer Religion, der die Kategorie der Unvereinbarkeit, wie sie jede "Orthodoxie" notwendig impliziert, von Haus aus fremd ist? Aus diesen Bedenken heraus habe ich das Wort "Häresie" in Anführungszeichen gesetzt. Die ägyptische Religion ist gewiß nie mit dem Ausschließlichkeitsanspruch einer Orthodoxie aufgetreten. Aber hier zeigt sich bereits ein erster struktureller Gegensatz zur Amarna-Religion, für die eben dieser Anspruch und die damit verbundene Kategorie der Unvereinbarkeit bestimmend wird ${ }^{32}$. Hier sind die Grenzen zwischen Orthodoxie und Häresie scharf gezogen. Aus Texten und Darstellungen ist mit empfindlichster Genauigkeit alles verbannt, was mit der neuen Lehre unvereinbar ist. So hat sich die Amarna-Religion selbst in einen so unversöhnlichen Gegensatz zur traditionellen Religion gestellt, daß hier die Begriffe Orthodoxie und Häresie - auch mit vertauschter Zuordnung - anwendbar werden.

Die monotheistische Sonnenreligion, die sich uns mit dem Namen „Amarna" verbindet, gilt einem Gott, den wir Aton oder richtiger Jät $i^{33}$ nennen, der aber in Wirklichkeit einen wesentlich längeren Namen trägt. Dieser Name, der eher so etwas wie eine Doxologie, eine theologische Wesensbestimmung darstellt, lautet übersetzt ungefähr:

${ }_{28}$ Der amerikanische Literaturwissenschaftler Kenneth Burke hat dafür den Terminus „temporizing of essence" geprägt (Myth, Poetry and Philosophy, in: Language as Symbolic Action [1966] S. $380 \mathrm{ff}$. ders., A Grammar of Motives [California edition 1969], 430-40.)

29 CT II 396; III 382 s. Otto, in: Saeculum 14, (1963) S. 256 und 277 f.; Hornung, Der Eine und die Vielen (1971), S. 166 und $170 \mathrm{f}$.

$3 n$ Vgl. besonders Hornung, op. cit. (Anm. 29) S. 164-179.

31 Diese Fragen stehen im Zentrum des neuen Werkes von Erik Hornung (op. cit. [Anm. 29]), das, wie mir scheinen will, den metaphorischen Charakter dieses Modells als eines neben anderen möglichen nicht ausreichend berücksichtigt, und die Dinge daher vielleicht etwas klarer sieht, als sie wirklich sind: "Die absolute Einheit Gottes findet der Ägypter nur jenseits der Schöpfung" (ebd., S. 181). Nach meinem Verständnis ist dieses "Jenseits der Schöpfung" eine neben anderen Metaphern (vgl. etwa die Konzeption des Gottes „Der seinen Namen verbirgt") für den Anwesenheitsmodus des Einen in der Vielheit, d. h. in der Schöpfung, um die es dem Ägypter eigentlich geht. An einer anderen Stelle seines Werkes, wo er diese dialektische Struktur mit dem Begriff der Komplementarität beschreibt, kommt Hornung meiner Auffassung jedoch sehr nahe (S. 233-40).

32 Das betont sehr zu Recht Hornung, bes. S. 242-246.

${ }^{33}$ Zur Vokalisation von $j t n \mathrm{~s}$. Fecht, in: ZAS 85 (1960) S. 84-88. 
„Es lebt Re-Harachte, der im Horizont jubelt, in seinem Namen als das Licht, das in der Sonne ist. " ${ }^{34}$

In Beziehung zur traditionellen Konzeption gesehen bedeutet diese Formel, daß der Gott, der dem Kult in vielen Namen zugänglich war, als Re, Chepre, Atum, Harachte, jetzt nur noch in einem Namen zugänglich ist, und dieser eine Name entspricht nicht einer symbolischen Gestalt (Falke, Mensch, Widder oder Skarabäus), sondern der einen konkreten Erscheinungsform des Sonnenlichts, in der sich der Gott nicht nur selbst offenbart, sondern auch - in Gestalt der Strahlen - auf die Erde herabkommt ${ }^{35}$. Das Vorkommen dieser Namensformel und damit die Geschichte des Gottes ist an die Regierungszeit Amenophis IV. gebunden. Es gibt keine Belege, die vor das Datum seiner Thronbesteigung zurückreichen, und andererseits kein Denkmal dieses Königs, das die Formel nicht enthielte. Schon auf seinen allerersten Stelen und Bauten ist sie zu finden.

Es dauert etwas länger, bis sich der neue Gottesbegriff auch in der Ikonographie ausprägt. Eine Zeitlang wird der Gott Amenophis' IV. noch wie der alte Sonnengott als falkenköpfiger Mann mit der Sonne auf dem Kopf dargestellit ${ }^{36}$. Dann aber - diese Wende muß ungefähr im vierten Regierungsjahr erfolgt sein - zeigen mit einem Schlage alle Denkmäler den neuen Gott nur noch in einer einzigen Gestalt, die alle traditionellen therio- und anthropomorphen Elemente abgestreif hat ${ }^{37}$. In diesen Bildern ist stets oben die Sonne, unten der König dargestellt, meistens wie er, in Begleitung der Königin und oft auch seiner Töchter, ein Opfer darbringt. Von der Sonne gehen lange Strahlen aus, die eine Verbindung zwischen der Sonne im Himmel und dem Vorgang auf Erden herstellen. Diese Verbindung wird dadurch betont, daß die Strahlen in Händen enden. Mit diesen Strahlenhänden berührt die Sonne den König und seine Opfergaben; einzelne Strahlen halten auch ihm und der Königin die Hieroglyphe "Leben" an die Nase.

Diese strahlende Sonne stellt den Gott dar. Um jeden Zweifel auszuschließen, werden ihr stets die lange Namensformel und eine Titulatur beigeschrieben, die mit den Worten "Die Große Lebende Sonne" beginnt ${ }^{38}$.

${ }^{34}$ Ubersetzung und Verständnis dieser schwierigen Formel sind in Einzelheiten noch immer umstritten. Die wichtigsten Beiträge stammen von Sethe, Beiträge zur Geschichte Amenophis IV, in: NAWG (1921) S. 101-130; Gunn, Notes on the Aten and His Names, in: JEA 9 (1923) S. 168 bis 176; Bonnet, in: Reallexikon der ägyptischen Religionsgeschichte (1952) S. 59-71; Fecht, Amarna-Probleme (II) in: ZAS 85 (1960) S. 99 ff.; Anthes, in: ZAS 90 (1963) S. 1-6; Bennett, in: JEA 51 (1965) S. 207-209.

${ }_{35}$ Diese Gleichsetzung von Name und Licht bedeutet also nicht, daß der Gott „Licht" he i $\mathrm{t}$ (das wäre ägyptisch $m$ rn.f $n$ Šw „in seinem Namen ,Licht $t^{\varsigma \alpha}$ ), sondern daß der ,Name ${ }^{6}$ des Gottes (im Sinne von „kultisch zugänglicher, anrufbarer Aspekt") sich im Licht materialisiert. Vgl. die formal entsprechende (inhaltlich entgegengesetzte) Aussage im Pap. Leiden J 346,iii, 10 (oben, Anm. 26). Zum „Licht, das in der Sonne ist" vgl. Pap. Leiden J 347, viii,2: „Ich bin der Lichtglanz, der in der Sonne ist".

${ }^{36}$ Berlin 2072 (Lepsius, Denkmäler III 110d vgl. oben Anm. 11 unter 2.); Aldred, in: JEA 45 Tf.iii p. 19 fig. 1 ; als Falke mit Sonnenscheibe, in: ASAE 40, Tf. 53-54.

${ }_{37}$ Die einzelnen Stadien dieser Entwicklung, die er allerdings ohne zwingenden Grund auf ein bis zwei Jahre zusammendrängen will, schildert Aldred, in JEA 45 (1959) S. 19-33. Seiner These einer 12jährigen Korregentschaft kann ich jedoch nicht zustimmen. Meine Auffassung entspricht weitgehend der Darstellung von Hornung, Untersuchungen zur Chronologie und Geschichte des Neuen Reiches, in: Ä. Abh. 11 (1964) S. $71-94$.

${ }^{38}$ "Du Große, Lebende Sonne" ist auch die übliche Anrede des Gottes in Hymnen und Anrufungen. Diese oder ähnliche Wendungen sind außerhalb Amarnas nicht belegt. In der Verbindung von "Sonne" und "lebend" liegt demnach ein häretisches, d. h. nur im Zusammenhang der AmarnaReligion denkbares Moment. Es besteht eben in der ungeheuren Ausweitung der Sonnenvorstellung, 
Einem ägyptischen Betrachter mußten diese Szenen jedoch auf den ersten Blick nicht so sehr als Sonnendarstellungen erscheinen, sondern ihm vielmehr den Begriff "Licht" vermitteln. Das Zeichen der strahlenden Sonne determiniert in der ägyptischen Schrift alle Wörter für "Licht“ und kann, wo es allein steht, als Ideogramm für $j 3 b w$, „Lichtglanz“, gelesen werden. Die neue Gottesdarstellung läßt sich als eine Ausgestaltung der LichtHieroglyphe interpretieren. So hat man wohl auch den Gott der Amarna-Religion nicht nur als Sonnen-, sondern vielmehr als Lichtgott aufzufassen. Das Licht ist aber in Ägypten nie vorher kultisch verehrt worden, und ebensowenig hat es je in Szenen des Sonnenkults eine Darstellung gefunden.

Das Licht bezeichnet die dogmatische Namensformel als den „Namen“ des Gottes. Damit ist die Form gemeint, in der er dem Kult zugänglich ist, oder, wie es die spätere Fassung der Formel noch deutlicher sagt: „kommt" 39 . Diese P a r u s i e des G ot t e s i m $\mathrm{L}$ i c h t ist der neue Gedanke, der alles verwandelt. Er verdrängt den Mythos mit seiner anthropomorphen Gottesvorstellung und den Kult mit seiner das mythische Götterdrama abbildenden Identifikation. Er verdrängt alle Formen symbolischer Repräsentation: der im Licht leibhaftig anwesende Gott läßt sich nicht bildhaft vergegenwärtigen ${ }^{40}$, und so führt auch der König persönlich die Opferzeremonien aus. Damit entfallen, um ein paar charakteristische Beispiele zu nennen, jene Wechselreden zwischen Gott und König, wie sie zum unabdingbaren Bestand jeder traditionellen ägyptischen Kultszene gehören, in denen der Austausch der Gaben und die eigentliche Bedeutung der symbolisch von Priester und Kultbild vollzogenen Handlung festgehalten wird. Auf keiner der zahllosen Opferszenen der Amarnazeit ist jemals eine Rede des Gottes an den König, und nicht einmal umgekehrt, erhalten. Dem Gott lassen sich keine Worte in den Mund legen, da er sich im Licht äußert, in den Strahlen, mit denen er auf die Erde herabkommt. Ferner ändert sich der Richtungssinn der Kultszene, die traditionell immer in der Horizontalen, hier aber in der Vertikalen verläuft. Die Erde wird nun nicht mehr im Vollzug des Kults dem Himmel abbildhaft angeglichen und damit im doppelten Wortsinn aufgehoben, sondern sie wird als Erde, oft noch mit liebevoller Angabe topographischer Details (Tempel, Palast, Ufergarten und Wüstenrand) dem Himmel gegenübergestellt. Der im Licht gegenwärtige Gott tritt zur Menschenwelt in eine ganz neue Beziehung. Die Welt wird nun zum reinen Objekt des belebenden Lichts - eben zu dem, als was sie in den älteren Darstel-

die nun nicht mehr als Gegenstand und dingliches Attribut des Sonnengottes gilt, sondern als seine leibhaftige, beseelte Verkörperung (bprw).

39 In der späteren, gewöhnlich in das 9. Regierungsjahr datierten Fassung des Namens heißt der Gott "Es lebt der horizontische Herrscher, der im Lichtland jubelt, in seinem Namen als Re, der Vater(?), "der als Sonne kommt". Auch in der traditionellen Sonnenreligion ist oft und ausführlich von der "Ankunf" des Sonnengottes die Rede: dort aber bezieht sich das immer auf die abendliche Ankunft des Sonnengottes in der Unterwelt, wo er den Toten leibhaftig erscheint (den Lebenden ist er nur fern am Himmel gegenwärtig), vgl. Liturgische Lieder, 46-48. In Amarna gibt es die Vorstellung eines jenseitigen Totenreichs und einer nächtlichen Descensusfahrt des Sonnengottes nicht mehr: hier „kommt“ der Gott am Tage und zu den Lebenden (nämlich als Licht auch auf die Erde), während er in der Nacht "fortgegangen", abwesend ist.

${ }^{40}$ Auf den Grenzstelen K und X („Earlier Proclamation") liest man den bemerkenswerten Satz „Die Bildhauer kennen ibn nicht" (Sandman, 11.7); die spätere Amun-Theologie, die viele Ansätze der Amarna-Religion in einen umfassenden Gottesbegriff einbringt, kommt in bezug auf den solaren Aspekt ihres Weltgottes Amun zu einer ganz ähnlichen Formulierung:

„Scharfer, Scharfer (= Wirkungsvoller), dessen Wesen man nicht kennt, die Bildhauer haben kein Modell von ibm,

(...), sein wabres Ausseben ist in den Scbriften nicht zu finden"

(unveröffentlichter Hymnus in den thebanischen Gräbern 106 und 65). 
lungen und Hymnen des Sonnenkults nie in Erscheinung getreten war. Die Welt wird vom Licht berührt, erfüllt und belebt. Das bedeutet aber für Amenophis IV. - und auch diese politisch-religiösen Konsequenzen einer zunächst eher physikalischen Einsicht lassen sich bereits der Ikonographie entnehmen - daß sie vom Licht beherrscht wird, beherrscht in dem ganz konkreten Sinne einer vom Lichtgott ausgeübten Königsherrschaft.

Denn so ist es zu verstehen, wenn die Namensformel des Gottes von jetzt ab stets in zwei „Königsringen" oder "Kartuschen" geschrieben wird, dem Symbol des ägyptischen Königtums, wenn der Gott eine Herrschertitulatur erhält, wenn nach Jahren des Gottes wie nach solchen Amenophis IV. datiert wird (wobei sich bequemerweise beide Zählungen vollkommen decken), und wenn auf königlichen Erlassen stets der Gott an erster Stelle im offiziellen Briefkopf erscheint ${ }^{41}$. Der Gott regiert mit und über dem König. Der monotheistische Ausschließlichkeitsanspruch ergibt sich aus dieser neuartigen Konzeption einer königlichen Alleinherrschaft des Lichtgottes von selbst. Was wir als die Einführung einer neuen Religion bezeichnen, stellte sich in der ägyptischen Begriffswelt als der Herrschaftsantritt des Lichtgottes dar. Diese Herrschaft ist aber nichts anderes als die Lichtstrahlung, von der die Welt lebt und abhängig ist und somit beherrscht wird. Die natürliche Lichtabhängigkeit der Welt ist es, die Amenophis IV. als Herrschaft des Lichtgottes gedeutet und in der Form einer neuen Religion durchgesetzt hat, die keine Götter mehr kennt, sondern nur noch das alles beherrschende Licht verehrt.

Diese Vision einer Alleinherrschaft des göttlichen Lichts hat sich der ägyptischen Wirklichkeit nicht einfach aufpfropfen lassen. Auch die ausgedehntesten Tempelbauten konnten das alte Theben nicht in eine neue Sonnenstadt verwandeln. Auf zuvieles, was ihnen nicht wohlgefällig sein konnte, fielen dort die Strahlen des Gottes. Der König, der seinen Namen nun in Echnaton, richtiger: Achanjati, ändert, was soviel heißt wie "der Sonne woblgefällig", sucht sich darum ein Gelände, das noch unberührt ist von jeglicher Tradition, wo sozusagen die „Urzeit“ noch gegenwärtig ist und die Schöpfung noch aussteht.

Und ist nicht Achanjatis Schritt in gewissem Sinne ein Rückgriff auf die Urzeit, als Göttliches Eines und die Zweiheit noch nicht entstanden war, eine Aufhebung der Vielheit und Differenziertheit der Welt? Dem entspricht, daß es im Weltbild von Amarna den Begriff der Urzeit nicht zu geben scheint; er spielt, sehr im Unterschied zur sonstigen religiösen Literatur des alten Ägypten, in den Texten keine Rolle. ${ }^{42}$ Hier ist die Urzeit aufgehoben und in die Gegenwart geholt. Die Schöpfung durch das Licht ist fortwährend im Gange. Der Eine ist aus der Verborgenheit in die Offenbarkeit getreten. ${ }^{43}$

41 Zum sog. „Protokoll", wie dieses offizielle „Formular" etwas irreführend in der Ägyptologie genannt wird, s. besonders Fecht, in: ZAS 85, S. 91-118. Das "Protokoll" gibt der Konzeption einer vom König verwirklichten Gottesherrschaft die Form der Korregenz, in der der Gott als "Vater", der König als "Sobn" regieren. "Vater", genauer "mein Vater" ist daher der offizielle Königstitel des Gottes, den er nur im Protokoll, also stets in Verbindung mit dem an zweiter Stelle genannten König, führt. Auch nach traditioneller Anschauung war in Agypten jeder König Sohn des Sonnengottes, der in der Vorzeit über Ägypten geherrscht hatte und dessen Erbe der König antritt. Für Amenophis $I V$. jedoch, das ist der entscheidende Unterschied, gehört die Herrschaft des Gottes nicht in die Vorzeit, sondern in die unmittelbare Gegenwart.

42 Auf einer Inschrift, die H. Brunner unlängst veröffentlicht hat (in: ZAS 97 [1971] S. 12-18), wird der Gott allerdings einmal "der erlaucbte Gott des Anbeginns" genannt. Aber diese Ausnahme, die nach Brunner in die Frühzeit des Königs gehört, bestätigt nur die auch von Brunner sehr klar hervorgehobene Regel. Wenn der erwähnte Grenzstelentext die Stadt Amarna als „seine (des Gottes) Stätte des Anbeginns" bezeichnet (Sandman, 105.5), so mag damit eben diese Unberührtheit, die „Gegenwärtigkeit des Urzustands" gemeint sein.

43 Aus diesen Gründen kann ich auch Westendorfs interessanten Thesen nicht ganz zustimmen, 
Mit der mythischen Kategorie der Urzeit entfällt jene zentrale Metapher, die das $\mathrm{Pa}$ radoxon der verborgenen Gegenwart des Urgottes zur Anschauung brachte. Diese Paradoxie wird nun rational aufgelöst als die „ferne Näbe" des Sonnengestirns, das zwar am Himmel allem Irdischen unerreichbar entzogen und in dieser ungeheuren Entfernung gleichsam verborgen ist und doch in Gestalt der Strahlen auf Erden (gerade kraft dieser Ferne) allgegenwärtig ist.

\section{„Du bist fern, aber deine Strablen sind auf Erden. \\ Du bist in ibren Gesichtern, aber man kennt deinen Gang nicht. ${ }^{\prime 44}$}

Die geheimnisvolle Beziehung des Einen zur Schöpfungswelt wird nun im Abstand zwischen Himmel und Erde verräumlicht. Der Eine ist so nicht mehr in der Schöpfung als der Vielheit verborgen gegenwärtig, sondern er steht ihr als Sonne gegenüber. In dieser fortdauernden Konfrontation mit dem einen Ursprung erscheint die Schöpfungswelt nun als undifferenzierte "Natur", als das homogene Produkt des Lichts.

Die Aufhebung der Vielheit äußert sich in der Verfolgung der alten Götter. Ihre Namen werden nicht mehr genannt und auf älteren Denkmälern ausgehackt. Sogar das Wort "Götter" fällt dieser Sprachregelung und damnatio memoriae anheim. Man geht schließlich so weit, auch das Wort "Gott" für den neuen Lichtgott zu vermeiden, der ja kein Gott im alten Sinne, keiner der alten Götter ist. ${ }^{45}$ Die derart entgöttlichte, homogenisierte Natur ist dem Gott nicht mehr in den Konstellationen einer "Sphäre des Seinigen" in vielgestaltigem Wechselspiel verbunden. Er steht allein am Himmel, der Welt gegenüber.

Andererseits darf aber diese Gegenüberstellung von Schöpfer und Schöpfung nicht auf eine dualistische Trennung und damit wieder auf die $Z_{w}$ eiheit herauslaufen. Daher geht die Amarna-Theologie in dem Bemühen, die Beziehung von Schöpfer und Schöpfung zu formulieren, bis an die Grenze völliger Identität, und in der Lichtterminologie der Texte prägt sich die Tendenz aus, die Beziehung so eng und so sinnlich-konkret wie möglich darzustellen. Die Lebewesen werden als Geschöpfe des Lichts mit Wendungen wie „alle Augen" und „alle Gesichter" bezeichnet, die d e n Teil fürs Ganze nehmen, der sie mit dem Licht verbindet. Das Licht aber wird als das Sehen Gottes gedeutet, als der Blick, mit dem er seine Schöpfung betrachtet. ${ }^{46}$. Durch das Sehen Gottes wird die Welt sichtbar und da-

der gewisse Eigentümlichkeiten der königlichen Ikonographie aus der Vorstellung von Aton als einem androgynen Urgott erklären möchte (in Pantheon 21 [1963], S. 269 ff.; vgl. auch Hornung, in: ZAS 97 [1971] S. 76 f.). Problematisch sind allerdings die Textstellen, wo von Atons Einsamkeit oder Alleinigkeit die Rede ist (Sandman, 15.4-6; 94.17; 95.11), und die man allgemein im Sinne der traditionellen Religion auf die Präexistenz des Gottes "jenseits der Schöpfung" bezieht (z. B. Fecht, in: ZAS 94, 33 n. 7). Statt "als du allein warst" läßt sich aber ebensogut übersetzen „indem $d u$ allein bist"; die Frage läßt sich grammatisch kaum entscheiden. Die CT bevorzugen allerdings für die traditionelle Konzeption eine andere Formulierung, die eindeutig perfektisch ist ( $m$ wn.f wcij, , als er allein war", z. B. CT II 39e, III 383c).

${ }_{44}$ Sandman 93.16-17, vgl. ebd., 95.12, in äußerster Knappheit, „du bist fern - du bist nab". Ich habe in MDIK 27.1, 8-10 einige hierhergehörende Stellen zusammengetragen.

45 Vgl. Hornung, op. cit. (Anm. 29) S. 244 m. n. 83.

46 Für diesen Gedanken lassen sich auch außerhalb Amarnas eine Fülle von Beispielen nachweisen. Er muß im ägyptischen Denken, für das "seben" und „sichtbar machen" (= leuchten), benachbarte, zuweilen austauschbare Begriffe sind, fest verwurzelt sein. Die Amarna-Konzeption baut auf solchen Vorstellungen auf und gibt ihnen systematische Bedeutung. Im "Großen Hymnus“ heißt es (Sandman, 95.10-11)

„Du hast den Himmel fern gemacht, um an ibm aufzugehen,

um alles $z u$ seben, was $d u$ geschaffen hast, indem du allein bist"

(bzw. „warst", vgl. n. 43; ähnlich im „Kleinen Hymnus“, Sandman 15.1 ff.). 
durch erst existent. Die Welt ist nur im Anblick ihres Schöpfers, der sie durch sein Sehen hervorbringt.

Aus dieser Konzeption resultiert jene Vorliebe der Amarnazeit für das Sichtbare, die man gern als "Freude an der Natur" verstanden hat. Das Sichtbare als das von Gott Geschaute und durch diesen Blick Erschaffene und Erhaltene verweist in seiner Geschöpflichkeit auf den Schöpfer. Was man als das „Naturgefübl“ der Amarna-Hymnen gerïhmt hat, ist der Aufweis dieser Geschöpflichkeit im Detail. Die kreatürliche Lichtabhängigkeit der Natur äußert sich in ihren Lebensregungen:

„Die Pflanzen, die auf dem Erdboden wachsen,

sie wachsen bei deinem Aufgang,

sie sind trunken vor deinem Angesicht.

Alles Vieh springt auf seine Füße, die Vögel, die in ibren Nestern waren, fliegen auf vor Freude;

ibre Flügel, die zusammengefaltet waren, spreizen sich in Lobgebärden

für die lebende Sonne, ibren Schöpfer." 47

Auch die Menschen reihen sich in diesen Lobpreis der Natur ein und loben den Schöpfer durch ihre bloßen respondierenden Lebensregungen:

"sie erwachen und steben auf ibren Beinen - du bast sie aufgerichtet.

Sie reinigen ibre Leiber, kleiden sich in weißes Leinen,

ibre Arme sind in Lobgebärden für dein Erscheinen;

das ganze Land tut seine Arbeit. " 48

Wo es um die huldigenden Lebensäußerungen der Wasserbewohner geht, kommen die Schiffe neben die Fische zu stehen:

„Die Scbiffe fabren stromauf und stromab, jeder Weg ist geöffnet durch dein Erscheinen.

Die Fische im Fluß hüpfen vor deinem Angesicht, deine Strablen sind im Innern des Ozeans. " ${ }^{49}$

Diesen Stimmungsbildern morgendlichen Auflebens stehen die Schilderungen abendlicher Todesbefallenheit gegenüber. Auch hierin äußert sich die Geschöpflichkeit einer Natur, der nur im Licht Leben und Wirklichkeit zukommt.

„Wenn du untergebst im Westen des Himmels, dann liegen sie wie im Zustand des Todes.

Ibre Köpfe sind verbüllt, ibre Nasen verstopf, bis du wieder aufgebst im Osten des Himmels. ${ }^{" 50}$

47 Sandman, 15.7-14 vgl. 94.6-8.

48 Ebd., 94.4-6.

49 Ebd., 8-10.

50 Ebd., 12-13. Für ähnliche Nachtschilderungen in den Amarnatexten s. Sandman, 7.13-14; 
Die angeführten Zitate klingen vertraut. Es gibt kaum andere Stellen in ägyptischen Hymnen, die sich so einfach, ohne jeden weiteren Kommentar, zitieren lassen. Tatsächlich verbindet uns gerade mit diesen Passagen einer dreieinhalb Jahrtausende zurückliegenden Liturgie ein direkter Traditionszusammenhang. Der Naturbegriff von Amarna, der die Welt auf den reinen Objekt-Status reduziert und ihr jedes differenzierte numinose EigenLeben abspricht, ist durch diese Entmachtung der Schöpfungswelt für die hebräische Religion akzeptabel geworden. So gingen die zitierten Abschnitte aus dem Großen Hymnus von Amarna in den 104. Psalm ein ${ }^{51}$, strahlten von dort in die hebräische Literatur aus und weit darüber hinaus bis in das evangelische Kirchengesangbuch unserer Tage. Daher erscheinen uns heute die Amarna-Hymnen in einem vertrauten Licht.

Aber diese Nähe trügt. Was diese Hymnen als Geschöpflichkeit aufzeigen wollen, die Lichtabhängigkeit der vom Licht geschaffenen Welt, läßt sich nur zu leicht als Gleichnis dessen verstehen, was Scbleiermacher das Gefühl "schlecbtbinniger Abbängigkeit" des Menschen genannt hat. In Amarna ist aber die Rede vom Licht nicht gleichnishaft, sondern buchstäblich als Rede von Gott gemeint. Hier steht kein persönlicher Gott lenkend und sorgend noch über Sonne und Licht, sondern in Sonne und Licht ist die Gottheit selbst gegenwärtig; nicht im Sinne einer Person, der sich der Mensch anbetend zuwenden kann, sondern im Sinne einer alles hervorbringenden Energie, an der der Mensch wie alle übrige Natur als Geschöpf teilhat. ${ }^{52}$

Man hat sich lange gescheut, diese Identität der Gottheit mit der Sonne für die AmarnaReligion zuzugestehen. Ist nicht, was dabei herauskommt, eine religionsgeschichtliche Ungeheuerlichkeit? Ist eine Religion überhaupt denkbar, die ganz ohne eine persönliche Gott-Mensch-Beziehung auskommt und die Frömmigkeit auf eine rein vegetabilische Lichtbezogenheit reduziert, auf die bloße Lebensregung und kreatürliche Abhängigkeit?

$23.5 ; 48.14-15-49.3 ; 52.13-14 ; 93-94 ; 95.17-18$. Außerhalb Amarnas ist Ahnliches nur im allerengsten zeitlichen Umkreis belegt, im Hymnus der Baumeister Suti und Hor (vgl. Anm. 11; Fecht, in: ZAS 94, 29, 35, 43 unten) und auf einer Stelle in Leiden (V 70 ed. Boeser, Beschreibung ... Leiden V Tf. 14).

51 Genauer sind es die Verse 20-30, die bis in die Formulierung hinein das Vorbild des Großen Hymnus verraten. Wie $F$. Crüsemann, Studien zur Formgeschichte von Hymnus und Danklied in Israel (1969) S. 286-288, zeigen konnte, fallen gerade diese Verse auch stilistisch aus dem Ganzen heraus. An dem Schluß, daß dieser Abschnitt auf eine eng mit dem Großen Amarna-Hymnus zusammenhängende Quelle zurückgeht, ist kaum ein $Z$ weifel möglich. Die neuerdings oft geäußerte Auffassung, daß auch zur Abfassungszeit des 104. Psalms in Ägypten noch Hymnen möglich waren, die dem Großen Amarna-Hymnus weitgehend entsprachen und zum Vorbild des hebräischen Textes werden konnten (z. B. Wilson, The Culture of Ancient Egypt (1951, 11. Aufl. 1968) S. 227 bis 229), ist u. A. auf Grund der Anm. 50 festgestellten Tatsache äußerst unwahrscheinlich. Eine „negative Wertung“ der Nacht ist in ägyptischen Hymnen späterer Zeit unmöglich.

52 Jubel und Gotteslob spielen in den Amarna-Hymnen eine weitaus bedeutendere Rolle als in den traditionellen Sonnenhymnen. Das könnte den Schluß nahelegen, daß hier im Gegenteil ein Gott gepriesen wird, für den die anbetende Zuwendung der Menschen in besonderem Maße charakteristisch ist. "Anbetende Zuwendung" und "kreatürliche Responsion" sind jedoch verschiedene Dinge. Daß es sich hier um das letztere handelt, läßt sich sowohl an der Lexik als auch an der Grammatik der Texte zeigen. Verben des Lobens und Jubelns stehen in einer Reihe mit solchen der bloßen Lebensregung, Ausdrücke für "Entzücken", „Jubeln", „büpfen“, „jauchzen", „in Freude“, „im Fest sein" sind weitaus häufiger als "anbeten" (Sandman 73.12), "huldigen", "preisen". "Menschen $^{*}$ erscheinen in diesen Stellen neben "Pflanzen" $(94.6-7 ; 76.3 ; 15.7-12)$, "Fischen ${ }^{\alpha}$ (94.9-10; 76.3), "Erde" (81.11), „Wildtieren" (15.10-12; 94.7-8), „Vögeln" (15.13-14; 94.7) usw. Die grammatische Form der „pseudoverbalen Konstruktion“ stellt (im Gegensatz zum finiten 
Solch eine Religion ist gewiß nicht denkbar, aber wer so argumentiert, übersieht, daß die Amarna-Religion um zwei Brennpunkte kreist: das Licht und den König. Wenn im Licht alle göttlichen Schöpfer- und Lebenskräfte zusammengeflossen sind, so sind im Königsbegriff von Amarna alle Formen einer persönlichen Gott-Mensch-Beziehung gleichsam monopolisiert. Das gilt in einem doppelten Sinn, sowohl für die Beziehung des Königs zum Sonnengott und seinen Strahlen, als auch für die Beziehung des Königs zum einzelnen Menschen. Wenn in den Texten der Sonnengott oft "Vater" genannt wird, so bezieht sich das stets auf den König, nicht auf die Menschheit insgesamt. ${ }^{53}$. Nur für den König offenbart sich in der Sonne ein persönlicher Gott.

\section{„Es gibt niemand, der dich kennte, außer deinem Sobn",}

heißt es im Großen Hymnus ${ }^{54}$, so daß auch bei Nacht, wie derselbe Text weiter ausführt, wenn für die Welt der Gott fortgegangen ist und alles Leben aussetzt, im Herzen des Königs Gott gegenwärtig bleibt. ${ }^{55}$ In Bezug auf den König haben dieselben Sonnenstrahlen, die am Morgen die Schöpfung ins Leben zurückrufen, einen anderen Sinn, den die bildende Kunst mit der Lebenshieroglyphe ausdrückt. Im segnenden Kontakt dieser Strahlen wird der König jeden Morgen aufs neue als Sohn des Sonnengottes geboren und verkörpert den Gott in seinem persönlichen Aspekt gegenüber den Menschen. ${ }^{56}$

Dies ist genau das Thema der Gottesdarstellungen, die immer Strahlensonne, Opfer und König umfassen, und diese Konstellation ist es, der sich die Devotion des Einzelnen zuwenden soll. In Amarna ist der König der Gott, der in Prozessionen auszieht und der jubelnden Menge erscheint, der die Bitten erhört, die Frommen belohnt, die Ungläubigen bestraft und sogar für das Leben nach dem Tode zuständig ist.

Ebenso klar wie in der Ikonographie spiegelt sich in der Tempelarchitektur von Amarna diese Konstellation aus Licht und König wider. ${ }^{57}$ Für das Licht haben diese Tempel

Verbalsatz) all diese Handlungen unter dem Aspekt des Zustands, der Befindlichkeit, dar, in die der aufgegangene Gott die Welt versetzt, nicht als spontanen Akt der Anbetung. Die sprachlose Unwillkürlichkeit dieses Gotteslobs drückt sich am klarsten in der Lieblingsformel der AmarnaHymnen aus: „ibre Arme sind in Lobgesten vor dir".

${ }_{53}$ Gewiß wird der Gott einmal mit den Worten gepriesen: „Du bist Mutter und Vater dessen, was du geschaffen hast" ("Kleiner Hymnus": Sandman 12.8-12). Aber das ist nicht im Sinne einer persönlichen Gott-Mensch-Beziehung zu verstehen, sondern gehört in den Kreis jener Aussagen, die Schöpfer und Schöpfung engstmöglich aufeinander beziehen, und versinnbildlicht die all-lebensspendende, all-fürsorgende Lebensenergie des Gottes, die alles, was lebt, einbegreif. Im Ǔbrigen handelt es sich hier um ein traditionelles Bild, das zunächst für den König (Urk IV 1077; ebenso LD III 140 d 3 s. Grapow, Bildliche Ausdrücke 132 n. 10), dann für den Sonnengott (Louvre C 67, Grapow, ebd. 133 n. 3; Theb. Grab 387 [1] = 106 [3], beide unveröffentlicht) und andere Götter (Osiris: in: ZAS 38, 30 f.; Geb: Grapow, ebd. 132 n. 12) gebraucht wird. Erst in einem viel späteren Text wird dieses Bild auf die individuelle Gott-Mensch-Beziehung angewendet (Kairo, Statue CG 42208, s. Otto, Die biographischen Inschriften der äg. Spätzeit (1954)

S. 142 m. n. 2): „Was ist denn Gott anderes für den Menschen als sein Vater und seine Mutter?"

54 Sandman, 95.16-17.

${ }^{55}$ Die Stelle ist schwierig und leider z. T. zerstört. Ich verstehe sie folgendermaßen: „wenn $d u$ fortgegangen bist, und es kein Auge mebr gibt, dessen Sebkraft du geschaffen bast, damit du nicht [allein] [deinen] Leib sähest [als] das einzige deiner Geschöpfe (der Leib), bist du (doch) in meinem Herzen (= Bewußtsein), indem es niemand gibt, der dich kennt..." Auch die Ergänzung "[meinen] Leib" und die Beziehung der Stelle auf den König scheint mir nicht undenkbar.

${ }^{56}$ S. dazu besonders L. Žabkar, in: JNES 13, 89-90; Drioton, in ASAE 43, 28 und 38.

${ }^{57}$ Für eine ausführlichere Darstellung dieser Gedanken s. meinen Aufsatz „Palast oder Tempel?“, in: JNES 31 (Juli 1972). 
offen zu sein, und da der Gott sie nicht bewohnt, sondern bestrahlt, müssen sie ebenso gleichmäßig mit Altären angefüllt sein, wie sie vom Licht erfüllt werden. Der Haupttempel von Amarna hat über 2000 solcher Altäre. Daß diese Tempel aber trotz so gleichförmiger Gotteserfülltheit den Weg von außen durch die einzelnen Höfe bis zum innersten Altar so stark hervorheben und die inneren Bereiche durch hohe Pylone gegen äußere abschirmen, kann sich nur auf den König beziehen, auf seinen Weg zum Altar und auf den Ort seiner Opferung als dem Allerheiligsten. Aber auch hier gehört die Strahlensonne dazu, um die Gottheit zu verkörpern: nicht nur die Höfe, auch der Weg haben ungedeckt zu sein, und die Säulenhallen müssen einen Mittelgang offen lassen, die Türstürze durchbrochen sein, damit die göttlich Konstellation aus König und Sonne nicht für einen Augenblick unterbrochen ist.

Außerhalb dieser Konstellation ist das Licht zwar göttlich, aber kein Gott, zu dem der Einzelne in Beziehung treten könnte. Er kann ihn nicht kennen und ebensowenig verkennen - er wäre ohne ihn gar nicht da. Was die Hymnen über diese Gott-Welt-Beziehung ausführen, ist daher weniger Theologie als vielmehr eine Naturlehre, eine Theorie vom Aufbau der Welt, die man als solche eher monistisch und nicht monotheistisch nennen sollte. Nur dem Licht wird ein Sein zugestanden, und der Welt nur insoweit, als sie am Licht teilhat. Sie entfaltet kein differenziertes schöpferisches Eigen-Leben. Mit jedem, Sonnenuntergang wird ihr Leben und Wirklichkeit wieder entzogen. ${ }^{58}$

Genau dieses differenzierte Eigen-Leben der Schöpfungswelt ist es aber, was als Erfahrung hinter der differenzierten Götterwelt der traditionellen Religion steht. Das Leben, das einmal am Urbeginn aus einem Ursprung entstand, wirkt nun als differenzierte Vielheit schöpferischer Kräfte innerweltlich fort. $\mathrm{Zu}$ dieser traditionellen Konzeption kehrte Ägypten zurück, als wenige Jahre nach Echnatons Tod unter Tutanchamun die alten Tempel wiederhergestellt und die Götter wieder kultisch verehrt wurden. Es ist jedoch symptomatisch für diese Rückkehr zur Orthodoxie, daß die Residenz nicht nach Theben zurück, sondern an einen dritten Ort: nach Memphis verlegt wurde. Man war offenbar nicht gewillt, die Episode von Amarna auszulöschen und da anzuknüpfen, wo diese mit der Tradition gebrochen hatte. Die religiösen Entwicklungen der Nach-Amarnazeit lassen sich nur als eine Auseinandersetzung mit den beiden zentralen Themen von Amarna, der Naturtheorie und der Königsideologie, verstehen. Der Königsideologie entspricht das Phänomen der sog. „Persönlichen Frömmigkeit“59, wo Gottheiten nun in genau jene Bindungen eintreten, die in Amarna für die Beziehung des Einzelnen zum König und des Königs zum Licht formuliert worden waren ${ }^{60}$. Der Naturtheorie aber entspricht der Ver-

58 Der Große Hymnus findet für diesen Gedanken die klarste und eindrucksvollste Formulierung (Sandman 95.17-18):

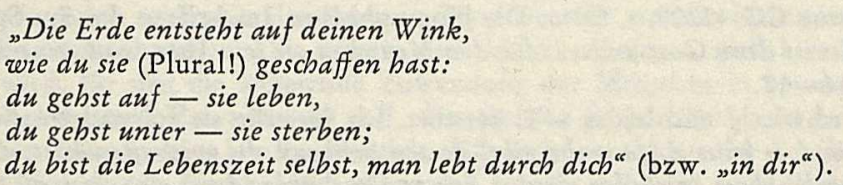

59 "Personal piety" s. Breasted, The Development of Religion and Thought in Ancient Egypt (1912), S. 349 ff., vgl. ferner Erman, Die Religion der Ägypter (1934) S. 139-156; Morenz, Ägyptische Religion (1960) S. 108-116; Otto in: Saeculum 14 (1963) S. 282-284.

${ }_{60}$ Diese These, deren ausreichende Begründung vermutlich eine Monographie in Anspruch nehmen würde, kann hier nur als Behauptung aufgestellt werden. Viele der für die Texte der „Per- 
such, das, was die Amarna-Hymnen als monistische Gott-Welt-Beziehung dargestellt hatten, in die Begrifflichkeit einer Beziehung von Gott zu Göttern zu übertragen, die wieder der Dialektik von Einheit und Vielheit Rechnung trägt. Der Große Hymnus von Amarna hatte die Beziehung Gottes zur Welt so formuliert:

\section{„Du erschaffst Millionen Gestalten aus dir, dem Einen:} Städte und Ortschaften, Felder, Weg und Fluß." 61

In der Nach-Amarnazeit ist erstmals die bis in die römische Zeit überlieferte Bezeichnung des Schöpfergottes belegt als

\section{„Der Eine, der sich zu Millionen macht. ${ }^{62}$}

In beiden Formulierungen geht es um den Einen und die Millionen, beidemale werden die Millionen als "Emanationen" (bprw) ${ }^{63}$ des Einen verstanden, der sich in Millionen vervielfältigt und doch Einer bleibt. Mit der Terminologie ist beiden Aussagen der monistische Ansatz gemeinsam. Der Unterschied liegt darin, daß in Amarna die Emanationen des Lichtgottes die beschienene Natur sind, während nach Amarna die Emanationen des Urgottes die unendliche Vielheit der innerweltlich wirkenden Kräfte, die Götter, meint. In Amarna wird also der monistische Ansatz radikal durchgeführt, nach Amarna wieder in eine komplementäre Struktur eingebunden, die mit der Einheit des Ursprungs die differenzierte Vielheit der Wirklichkeit verbindet.

Ist dies vielleicht letzten Endes auch nur eine "dogmatische Finesse", eine bloße Nuance? Ich glaube nicht. Gerade durch die Gemeinsamkeit des monistischen Ansatzes erweist sich die Lehre von Amarna als die genaue Gegenposition zur traditionellen Religion. Daher führte auch die Auseinandersetzung mit Amarna letztlich zu einer gedanklichen Verarbeitung des Alten und zu bewußter Ablehnung des Neuen. Das Urteil der Ramessidenzeit gegenüber Amarna lautete auf Häresie, und die zur Orthodoxie erwachte Tradition überzog dann Jahrzehnte später noch die Relikte der Amarnazeit mit demselben Strafgericht einer damnatio memoriae, mit dem diese erstmals als Orthodoxie gegenüber der Tradition aufgetreten war. Die Amarna-Religion hat als Herausforderung klärend, aber nicht reformatorisch wandelnd gewirkt. Die traditionelle Religion ist sich ihrer selbst in dieser Konfrontation mit ihrem Gegensatz nur umso bewußter geworden.

sönlichen Frömmigkeit" charakteristischen Formen (z. B. der "Makarismos") und Motive (z. B. der Komplex "Scbicksal $\left.{ }^{*}\right)$ lassen sich zuerst in Amarna nachweisen, und zwar in Texten, die von der Beziehung des Einzelnen zum König handeln. Manche dieser Königshymnen tauchen später außerhalb Amarnas sogar wörtlich als Götterhymnen auf, z. B. der Text Sandman, $24.12 \mathrm{ff}$. als Chonshymne auf der Statue Kairo 917.

61 Sandman, 95.12-13; vgl. zu dieser Stelle Fecht, in: ZAS 94 (1967) S. 33 m. n. 7.

62 S. hierzu Otto, in: Forschungen und Fortschritte 35.9 (1961) S. 278 f.; ders., Gott und Mensch nach den Tempelinschriften der griechisch-römischen Zeit (1964) S. 106; Hornung, Der Eine und die Vielen (1971) S. 164-166. Der früheste Beleg findet sich in einem theban. Grab aus der Zeit Sethos I. (Davies, Two Ramesside Tombs, Tf.ix unten) und bezieht sich, was sicher kein Zufall ist, auf Osiris. Später ist damit jedoch immer Amun-Re gemeint.

${ }^{63}$ Den Begriff der Emanation gebraucht Otto, in: Forschungen und Fortschritt 35 (1961) S. 278. Von den "Millionen bprw" des Sonnengottes spricht auch ein Weisheitstext, die "Lebre des Ani" (pBoulaq 4,vii,15 s. Volten, Studien zum Weisheitsbuch des Anii, S. 111-112, 115): „Er manifestiert sich in Millionen bprw. "Zur Gleichung bprw = Göttervielheit s. oben. S. 115, m.n.25. 


\section{Abkürzungsverzeichnis}

ASAE = Annales du Service des antiquités de l’Égypte (Kairo).

$\mathrm{CAH}=$ Cambridge Ancient History, 2. Auflage.

$\mathrm{CoA}=$ The City of Akhenaten I-III (= Egypt Exploration Society, memoirs 38 (1923), 40 (1933), 44 (1951).

CT = A. de Buck, The Egyptian Coffin Texts I-VII (1935-1961).

JEA = Journal of Egyptian Archaeology (London).

JNES = Journal of Near Eastern Studies (Chicago, Ill.).

MDIK = Mitteilungen des Deutschen Archäologischen Instituts, Abt. Kairo.

NAWG $=$ Nachrichten der Akademie der Wissenschaften zu Göttingen.

OMRO = Oudheidkundige Mededelingen uit het Rijksmuseum van Oudheiden te Leiden.

Sandman $=M$. Sandman, Texts from the Time of Akhenaten, in: Bibl. Aeg. VIII (1938).

Urk IV = Urkunden des ägyptischen Altertums, IV. Abteilung, Bd. 1-4 (1927-30) hg. v. K. Sethe, Heft 17-22 (1955-58) hg. v. W. Helck.

ZÄS $=$ Zeitschrift für ägyptische Sprache und Altertumskunde (Berlin). 